\title{
Descubrimiento y reporte de las primeras estepas altiandinas en Venezuela
}

\section{Discovery and report of the first Andean highland steppes for Venezuela}

\author{
Enrique La Marca, Escuela de Geografía, Facultad de Ciencias Forestales y Ambientales, \\ Universidad de Los Andes, Venezuela, enrique.lamarca@gmail.com \\ (1) https://orcid.org/0000-0002-6508-3375 \\ Yocelin B. Contreras C., Escuela de Geografía, Facultad de Ciencias Forestales y Ambientales, \\ Universidad de Los Andes, Venezuela
}

Resumen: Se hizo un levantamiento cartográfico y ecológico de un sector semiárido de los Pueblos del Sur de Mérida, en los Andes venezolanos, basado en la aplicación del modelo bioclimático de Zonas de Vida de Holdridge. Se detectaron cuatro zonas de vida para el área de estudio: monte espinoso Premontano, estepa espinosa Montano Bajo, estepa Montano y bosque húmedo Montano. Dos de las formaciones vegetales detectadas, la estepa espinosa Montano Bajo y la estepa Montano, constituyen dos Zonas de Vida que se reportan por primera vez para Venezuela. Las pequeñas dimensiones que éstas ocupan con respecto a la superficie del país y del estado explica en parte el por qué no habían sido detectadas previamente. Las Zonas de Vida de Venezuela ahora ascienden a un total de 24 , de las cuales 20 se localizan en el estado Mérida, incluyendo las dos nuevas que son exclusivas de éste. Todas las Zonas de Vida actuales en el área de estudio se caracterizaron desde el punto de vista geográfico. Se hizo una reconstrucción de Zonas de Vida en el área para el Último Máximo de Glaciación, donde se evidenció que las estepas altiandinas venezolanas ocuparon una superficie mayor en el pasado.

Palabras clave: Zonas de Vida; Estepa espinosa Montano Bajo; Estepa Montano; Biogeografía; Paisajes.

\begin{abstract}
A cartographic and ecological survey of a semi-arid sector of the Pueblos del Sur región of Merida, in the Venezuelan Andes, was made based on the application of the Holdridge's Life Zones bioclimatic model. Four life zones were detected for the study area: Premontane woodland, Lower Montane thorn steppe, Montane steppe and Montane moist forest. Two of the plant formations detected through this study, the Lower Montane thorn steppe and the Montane steppe, constitute two Life Zones that are first reported for Venezuela. The small dimensions they occupy with respect to the surface of the country and the state partly explain why they had not been previously detected. The Life Zones of Venezuela now amount to a total of 24 , of which 20 are located in the state of Mérida, including the two new ones that are unique to it. All current Life Zones in the study area were characterized geographically. A reconstruction of Life Zones was carried out in the area for the Last Glacial Maximum where it was evidenced that the Venezuelan high Andean steppes occupied a greater Surface in the past.
\end{abstract}

Keywords: Life Zones; Lower Montane Thorn Steppe; Montane Steppe; Biogeography; Landscapes.

\section{Introducción}

El estado Mérida es el que cuenta con la mayor diversidad de Zonas de Vida en Venezuela; alberga una gran diversidad de ambientes controlados principalmente por 
condiciones climáticas y otros aspectos geográficos como suelos, orientación y exposición de las montañas. Entre sus ambientes montanos destacan, por su relativamente escasa cobertura espacial y la poca comprensión de su dinámica ecológica, las formaciones vegetales secas de altura. De estas últimas, en los lugares relativamente más cálidos y menos elevados predomina una vegetación arbustiva espinosa y diferentes formas herbáceas, mientras que en las partes más frías y elevadas predominan herbazales.

En los Andes tropicales, al contrario de lo que ocurre en las latitudes templadas, las formaciones espinosas y herbáceas ubicadas a gran altura han sido poco estudiadas. En los Andes de Venezuela, en particular, estas formaciones empezaron a ser formalmente reconocidas sólo recientemente. Para la década de 1960 ya habían sido cartografiados a pequeña escala los ambientes xerofíticos intramontanos, mientras que para los ambientes secos de gran elevación esto demoraría hasta comienzos de los 70's. Las limitaciones de escala no permitieron la representación cartográfica de los ambientes de alta montaña tropical más secos y fríos. Por otra parte, en esos estudios basados en el sistema de unidades ecológicas, esos ecosistemas secos altiandinos quedarían 'enmascarados', el primero dentro del denominado 'Arbustal Siempreverde', y el segundo dentro de las formaciones vegetales conocidas como "Páramo".

El desarrollo de esta investigación nació de la inquietud por resultados encontrados en Trabajos Especiales de Grado que hemos dirigido en la Escuela de Geografía de la Universidad de Los Andes (Mérida, Venezuela), relacionados con formaciones vegetales dentro del estado Mérida. Estos muestran Zonas de Vida de estepa espinosa Montano Bajo y estepa Montano, como transiciones o como Zonas de Vida propiamente dichas, aunque de manera hipotética. Dado que aún no se había corroborado la existencia de las mismas, nos propusimos como objetivo en este trabajo determinar y cartografiar su ubicación, dar sus características ecológicas y las extensiones que ocupan actualmente, así como conocer su cobertura durante el Último Máximo Glacial.

\section{Materiales y métodos}

\section{1. Área de estudio}

El área de estudio se ubica dentro de la región de los Andes venezolanos, en la Sierra Nevada de Mérida, Venezuela, enclavada en áreas intramontanas secas de la cuenca del río Chama, específicamente en la margen izquierda del río Nuestra Señora. Geopolíticamente pertenece a la Parroquia Acequias del Municipio Campo Elías en el estado Mérida. Comprende un sector semiárido de $89,8 \mathrm{Km}^{2}$ ubicado dentro de un triángulo con ápices en los centros poblados (aldeas) de Tostós, Acequias y San Pedro (Figura 1), con un rango altitudinal desde 1700 metros sobre el nivel del mar (msnm) hasta los $3616 \mathrm{msnm}$. 


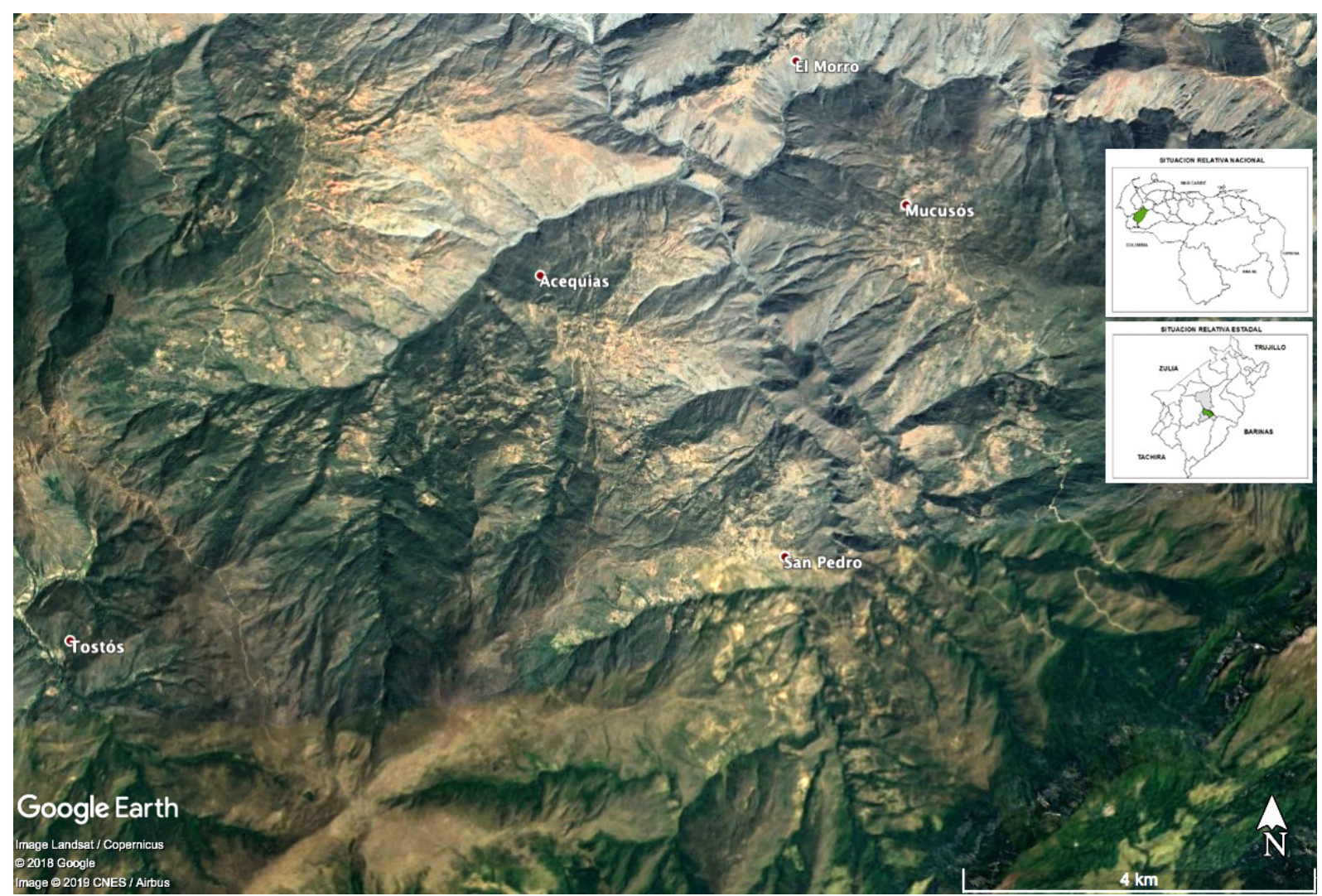

Figura 1: Imagen satelital de Google Earth $®$, que muestra a grandes rasgos el área de estudio entre el triángulo definido por las aldeas Tostós, Acequias y San Pedro (Estado Mérida, Venezuela).

\subsection{Material cartográfico}

El material base lo constituyó las cartas geográficas del año 1975 de la Dirección de Cartografía Nacional (DCN Venezuela) 5941 II NO, 5941 II SO, 5941 III NE y 5941 III SE, a escala 1:25.000, el Mapa de Geología del Ministerio de Minas e Hidrocarburos del año 1976, a escala 1:500.000 y una imagen Spot del año 2010, con resolución de 8 metros. Con el material cartográfico se elaboró un mapa base sobre el cual se vertió toda la información resultante. Este también sirvió de apoyo para cinco salidas de campo que cubrieron la totalidad área de estudio en recorridos por carreteras asfaltadas, sin pavimentar, caminos de recuas y a través de excursiones a pié, cubriendo desde los 800 hasta los $3122 \mathrm{msnm}$, y pasando por las localidades de Las González, El Morro, Acequias, ruinas de Mucuñó, San Pedro, Tierra Negra, San José, Páramo de Piedra Pirela, y Laguna Las Lajas en el Páramo de San Gerónimo o de Acequias.

\subsection{Datos y cálculos climatológicos}

Seleccionamos las estaciones El Morro (serial 3080); Tostós (serial 8057), Chacantá (serial 3138) y San Juan de Lagunillas (serial 3170), con años de registros de precipitación entre 1971 y 1990. Los únicos registros de temperaturas (período 19811983) corresponden a esta última estación. Para la extrapolación de temperaturas se empleó el gradiente altotérmico propuesto por Vivas (1992) para la cuenca del río Chama, que es de $0,6^{\circ} \mathrm{C}$ por cada $100 \mathrm{~m}$ de elevación. Los valores de temperatura se 
ajustaron a las curvas de nivel, cada 20 metros, obtenidas del Shuttle Radar Topography Mission (SRTM) de la NASA. Con esos datos se crearon mapas de isoyetas e isotermas.

\subsection{Determinación de Zonas de Vida}

Las Zonas de Vida (asociaciones vegetales dentro de una división natural del clima) fueron determinadas según el modelo de Holdridge (Figura 2) como fuese detallado en Ewel et al. (1976).

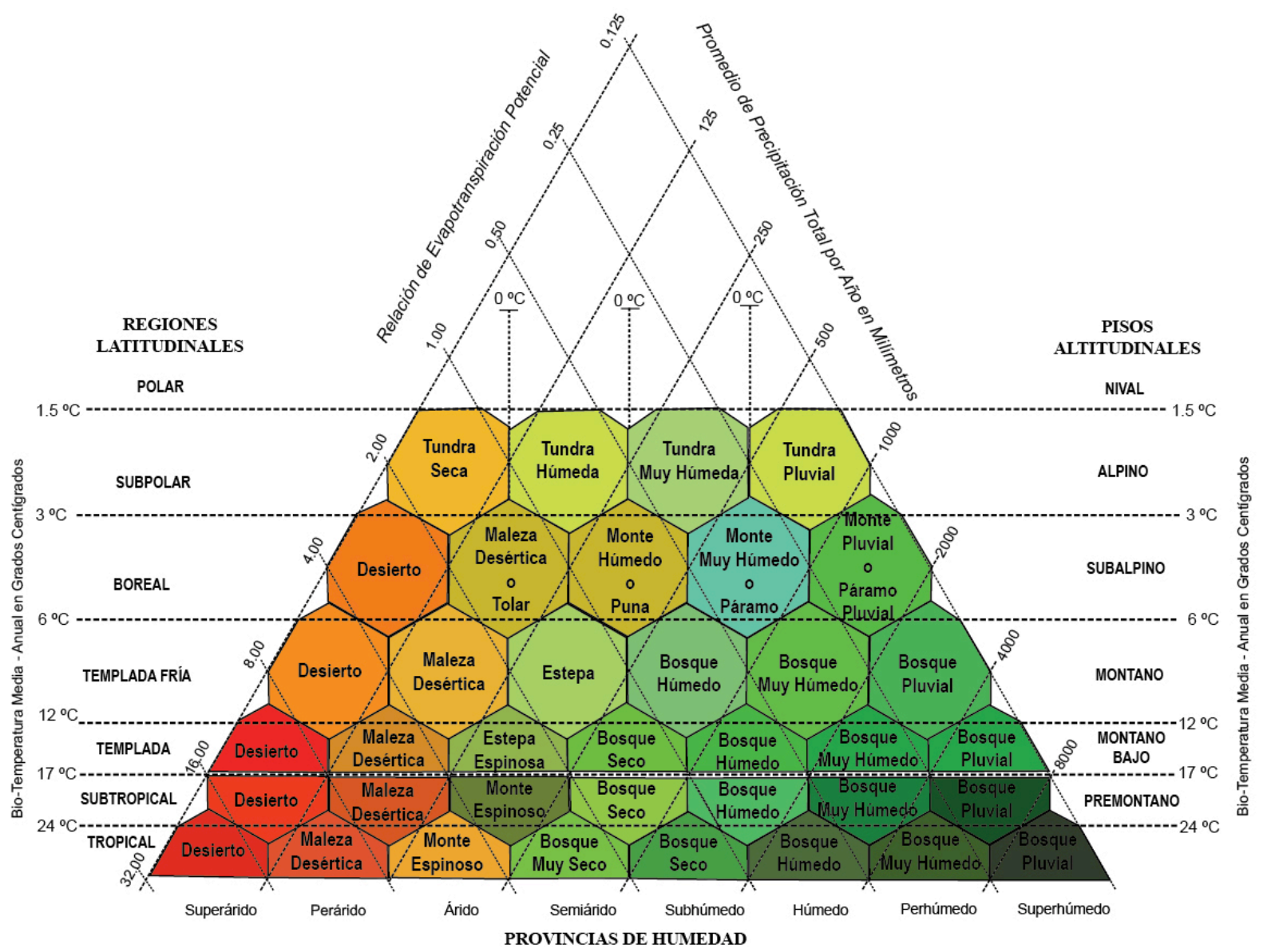

Figura 2: Modelo bioclimático de Zonas de Vida. Elaboración propia, basado en Ewel et al. (1976).

Cada Zona de Vida actual la determinamos mediante superposición de los mapas de temperatura y precipitación donde se generaron los diferentes polígonos. Para generar las Zonas de Vida en el pasado, específicamente durante el Último Máximo de Glaciación (regionalmente conocida como "Glaciación Mérida") nos basamos en estudios previos en los Andes del Norte (Van der Hammen, 1974), en Venezuela (Schubert y Vivas, 1992), y en trabajos inéditos de nuestro Laboratorio de Biogeografía de la Universidad de Los Andes en Mérida, que sugieren que hubo un descenso promedio de la temperatura de $5{ }^{\circ} \mathrm{C}$, y una disminución de $25 \%$ para la precipitación, en relación con los valores actuales. 


\subsection{Balance hídrico del suelo}

Para el cálculo del balance hídrico del suelo, solamente para las zonas de Vida de estepa espinosa montano Bajo y estepa Montano ubicamos seis puntos de muestreo en dos formaciones geológicas diferentes y con diferentes grados de pendiente, como se indica:

Punto 1 ( $8^{\circ} 27^{\prime} 37^{\prime \prime} \mathrm{N}$ y 71017'41'W, 2420 msnm), Asociación Tostós, en Zona de Vida estepa espinosa Montano Bajo, pendiente 25 a 45 grados, capacidad de campo 4,4.

Punto 2 (8²5'25'N y 71012'10'W, 1900 msnm): Asociación Tostós, en estepa espinosa Montano Bajo, pendiente de 15 a 25 grados, capacidad de campo 9,2.

Punto 3 ( $8^{\circ} 23^{\prime} 55^{\prime \prime} \mathrm{N}$ y 71012'08'W): Asociación Mucuchachí, en estepa Montano, pendiente de 25 a 45 grados, capacidad de campo 7,2.

Punto 4 (8²3'59'” y 7116'39'W, 3180 msnm): Asociación Mucuchachí, en estepa Montano, pendiente de 25 a 45 grados, capacidad de campo 7,2

Punto 5 (26, 8²2'28'N y 71¹3'52'W, 3100 msnm): Asociación Mucuchachí, en estepa espinosa Montano Bajo, pendiente de 0 a 15 grados, capacidad de campo 7,8 .

Punto 6 (8²2'28'N y 71013'52'W, 3100 msnm): Asociación Mucuchachí, en estepa Montano, pendiente de 0 a 15 grados, capacidad de campo 7,8.

\section{Resultados}

\subsection{Aspectos físico-geográficos}

El relieve del área de estudio es montañoso, con predominio de pendientes de moderadas a fuertes (entre 15 y 45 grados). Las pendientes de $0-15^{\circ}$ están asociadas a los fondos de valle y crestas, las del rango $15-25^{\circ}$ en los contactos entre vertiente y fondos de valle; las de rango $25-45^{\circ}$ predominan en el área y se localizan a lo largo de las vertientes; las del rango $45-55^{\circ}$ ocupan áreas muy pequeñas, en su mayoría al norte del área de estudio; y las pendientes $>55^{\circ}$ son las de menor extensión, asociadas con vertientes muy escarpadas.

La hidrografía presenta toda una serie de drenajes sin toponimia en la cartografía oficial. Las quebradas más importantes son Mocheré, Mucumpís, Mucusás, Mucutirí y La Capellanía, todas de régimen permanente. Las quebradas Mucumpís y Mucutirí nacen en el filo de Mucutirí y forman unos de los tributarios de la quebrada Tostós, que a su vez es afluente del río Nuestra Señora, el más grande en el área de estudio (Figura 3). 


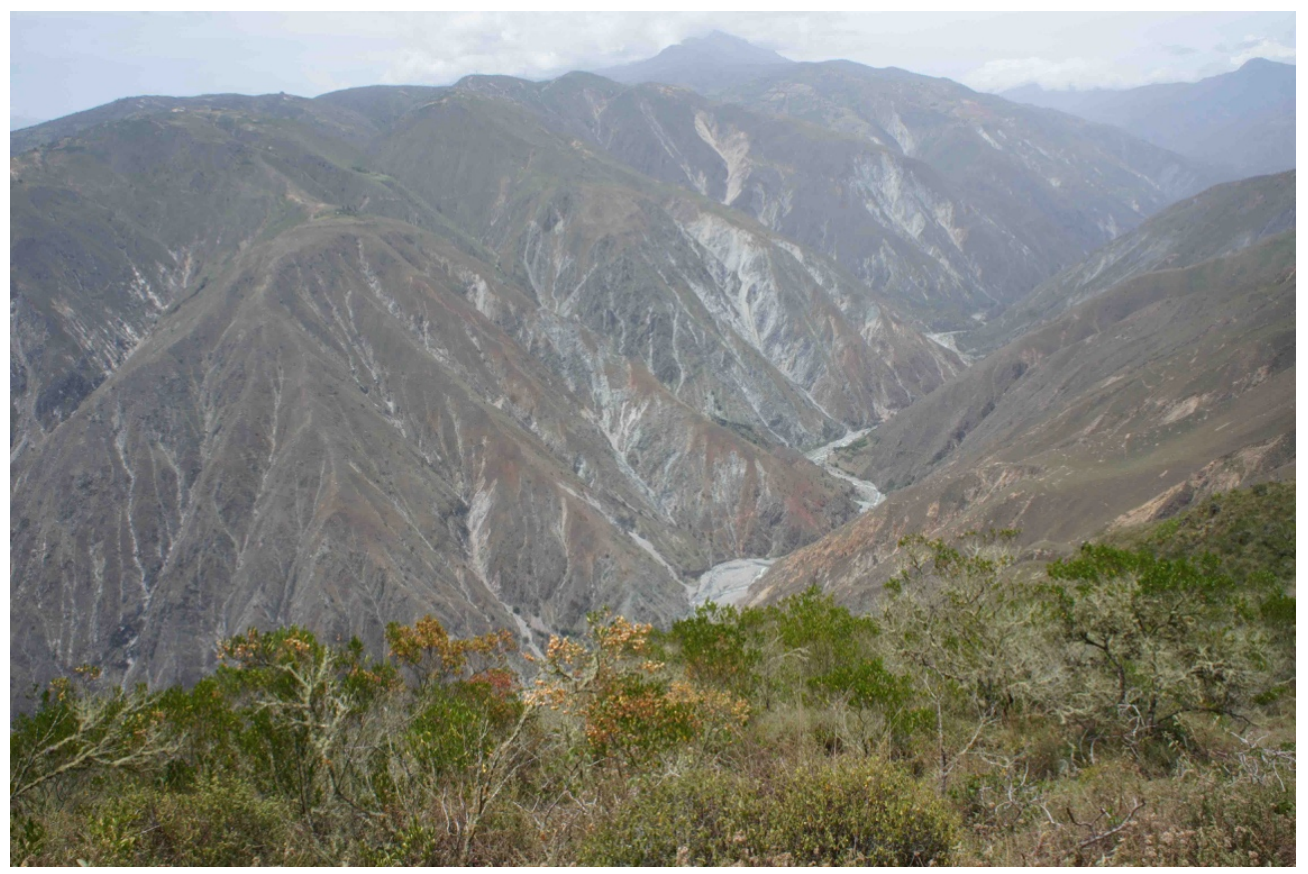

Figura 3: Valle del río Nuestra Señora visto desde el área de estudio.

Foto: E. La Marca.

Las formaciones geológicas en el área de estudio están constituidas por rocas metamórficas pertenecientes a la Asociación Mucuchachí (al sur y al este del área de estudio, y la que mayor superficie ocupa) y la Asociación Tostós (al norte del área de estudio, Figura 4). Estas son dos de las unidades litoestratigráficas más importantes del Paleozoico y de las más antiguas en los Andes Venezolanos (La Marca, 1997).

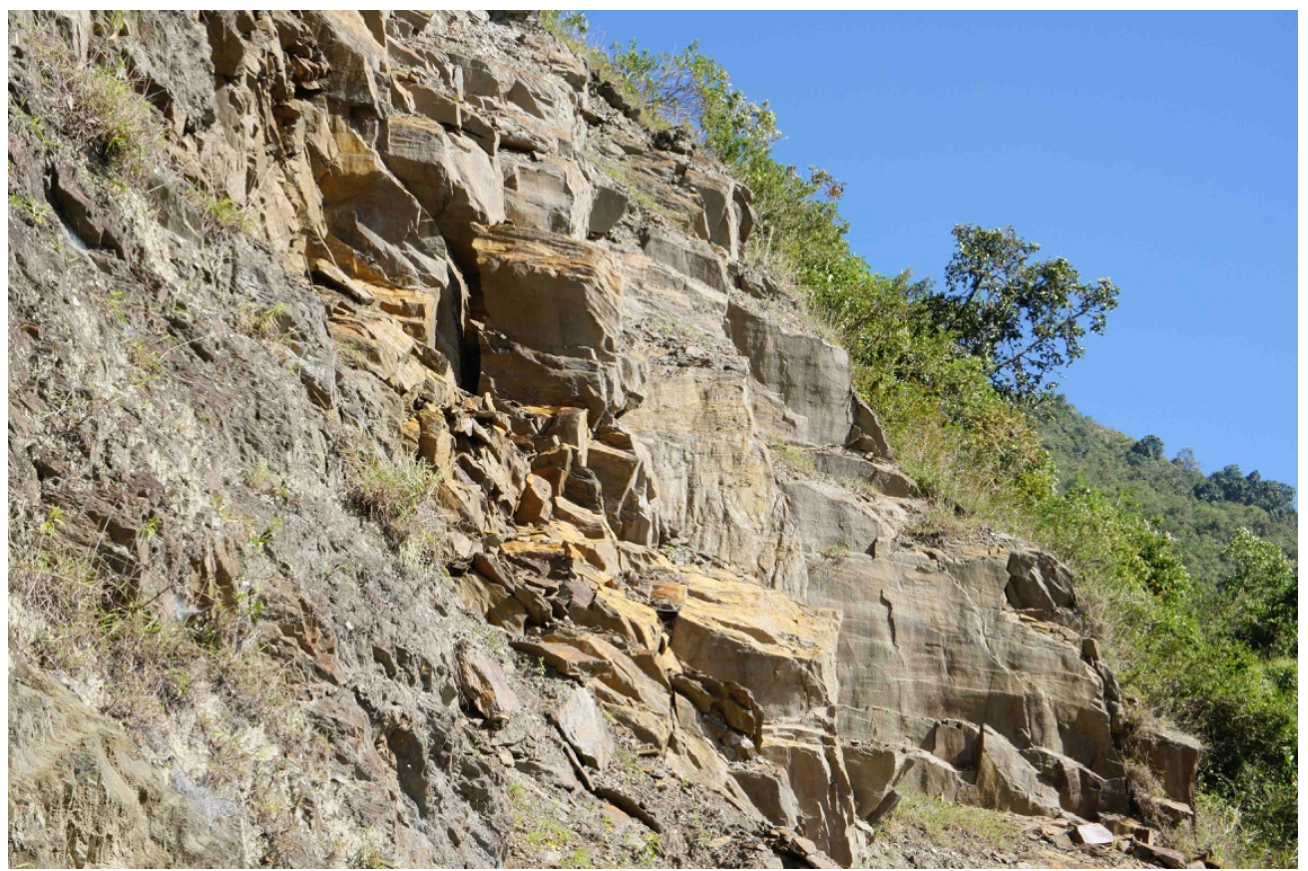

Figura 4: Afloramiento de la Asociación Tostós en la carretera entre Mocheré y Mucutirí, Pueblos del Sur de Mérida.

Foto: E. La Marca. 
Los suelos desarrollados en la Asociación Mucuchachí son de color rojizo, con textura franco-arenosa y muy erosionados. Los suelos de la Asociación Tostós son de color pardo oscuro, con texturas de finas a gruesas y medianamente profundos. La escasa cobertura vegetal en el área condiciona que los suelos posean poca retención de humedad, mala estructuración, poco contenido de materia orgánica y un pobre desarrollo del horizonte superficial, lo cual contribuye a acelerar los procesos erosivos y aumentar el grado de aridez.

El análisis del balance hídrico del suelo en diferentes puntos del área de estudio (véase sección de Métodos) reveló los siguientes aspectos: las temperaturas son elevadas y las precipitaciones son bajas a lo largo del año, mientras que la evapotranspiración potencial (ETP) supera siempre la precipitación (es decir, toda el agua que cae y la que almacenan plantas y suelo se evapotranspira, quedando el suelo sin reserva de agua durante todo el año, dando un déficit hídrico) en los puntos 1, 2 y 5; a excepcion del mes de mayo en el punto 3 (Figura 5) y los meses de mayo y octubre en los puntos 4 y 6 , cuando la ETP supera la precipitación. Los resultados indican que la estepa espinosa Montano Bajo durante todo el año presenta un déficit hídrico en el suelo que contribuye con las condiciones de sequía del ambiente (que se suman a las condiciones climáticas semiáridas), mientras que en la estepa Montano durante dos meses se produce una pequeña recarga de humedad.

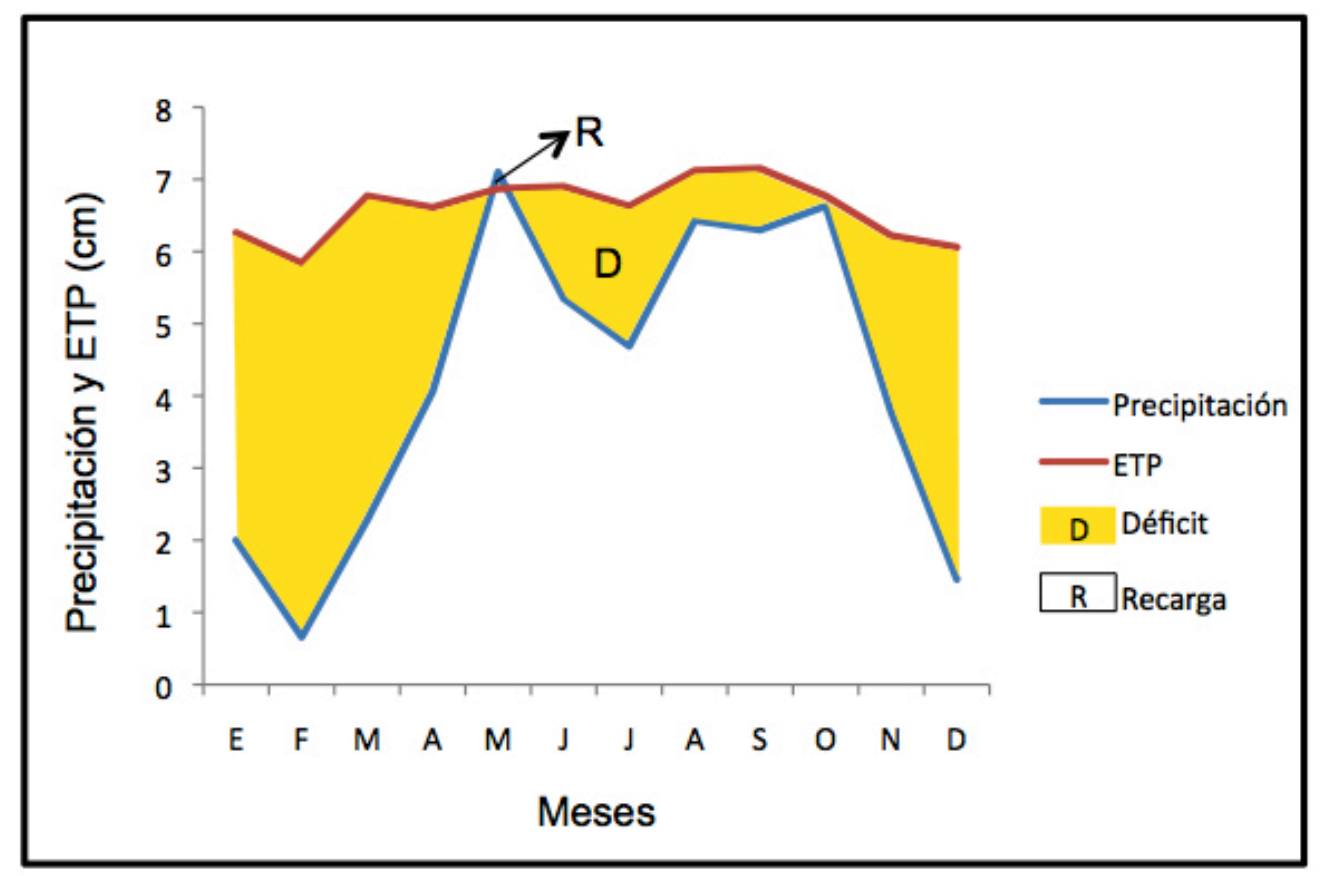

Figura 5: Balance hídrico del suelo en el punto 3 (período 1971-1990).

\subsection{Clima}

El clima del área de estudio está influenciado por el bolsón semiárido de Lagunillas (Andressen, 2009) producto de una acción combinada de sombra de lluvia y de efecto Föehn. El régimen de precipitaciones predominante en el área de estudio es el 
tetraestacional del Lago de Maracaibo. Este patrón, también denominado 'lacustre', está caracterizado por presentar de forma estacional dos máximos (abril a mayo, septiembre a noviembre) y dos mínimos (febrero a marzo, junio a agosto) de lluvias (Santiago-Paredes y La Marca, 2007). En las partes más elevadas del área de estudio (páramo de San Gerónimo o de Acequias), el régimen de precipitaciones es el biestacional de los Llanos de Venezuela (con un máximo de lluvias en mayo o junio y un mínimo en enero o febrero), que pudiera explicar la mayor condición de humedad en la zona. Las precipitaciones en el área de estudio oscilan entre 455 y $510 \mathrm{~mm}$ de promedio anual.

La variación intra-anual de la temperatura no es muy marcada, con un régimen isotérmico donde la amplitud térmica entre el mes más cálido y el mes más frio es menor a $5^{\circ} \mathrm{C}$. Con el cálculo de las isotermas al relieve por gradiente altotérmico, entre los 1660 y los $3620 \mathrm{~m}$ de elevación, la mayor temperatura $\left(18,6^{\circ} \mathrm{C}\right)$ se da a 1660 msnm., descendiendo $\left(a 7^{\circ} \mathrm{C}\right)$ en el páramo de San Gerónimo o de Acequias, a los $3620 \mathrm{msnm}$.

Constatamos que los vientos alisios provenientes de los Llanos occidentales de Venezuela ascienden por las laderas del sur de la Sierra Nevada de Mérida, por la cuenca del río Mucuchachí, al sur del área de estudio (vertiente llanera), y condensan en nubes cargadas de humedad que precipitan en forma de lluvia a media montaña condicionando la aparición de bosques húmedos y bosques nublados. Cuando estos vientos se encuentran con las montañas elevadas que conforman el páramo San Gerónimo y otros cercanos, algunas de las nubes formadas por condensación orográfica logran sobrepasar las altas cumbres, mientras que una gran mayoría queda suspendida sobre esta área, originando condiciones más húmedas que se reflejan en una vegetación más diversa. Por el contrario, el páramo Piedras Blancas se encuentra casi siempre sin cobertura de nubes, ya que los vientos húmedos provenientes del sur quedan atrapados por toda una barrera de páramos (El Cupíz, Piedra Pirela y San Gerónimo, entre otros) y parte de esos vientos descienden como vientos secos (tipo Foehn) hacia la cuenca del río Nuestra Señora. Las nubes cuando descienden se calientan, lo cual hace que disminuya su humedad relativa y se disuelvan (desaparecen).

La influencia del clima semiárido de la región de Lagunillas hace que perduren los días despejados, ocasionando que en el páramo Piedras Blancas se acentúen las condiciones secas, con una alta radiación solar y elevada evapotranspiración. Son precisamente estas condiciones secas, junto con las bajas temperaturas dadas por la elevación, las que favorecen el establecimiento de la vegetación herbácea, tipo pajonal, dominada por gramíneas.

Además de estos vientos que se originan en los Llanos occidentales de Venezuela y que bajan por las vertientes norte y noroeste de la Cordillera de Mérida como vientos secos del tipo Foehn, hay vientos secos descendentes de la opuesta Sierra de La Culata, luego de haber descargado lluvias en la vertiente andino-lacustre. La influencia fisiológica de estos vientos, que hace bajar la humedad relativa a porcentajes 
inferiores al $20 \%$, se traduce en una mayor evapotranspiración de las plantas; esta última se incrementa aún más por la alta insolación en el área (entre 400 y 450 calorías $/ \mathrm{cm}^{2}$ ) que está entre los mayores valores para Venezuela (Veillon, 1989).

Los vientos de valle que vienen del sur del Lago de Maracaibo, con una orientación predominante SW a NE, y que llegan como vientos secos a la región de Lagunillas, no logran ascender libremente por el valle del río Nuestra Señora. La disposición encajonada de este río y la vuelta en "U" que da su cauce poco antes de verter las aguas al río Chama actúan como barrera que limita que los vientos asciendan y puedan aportar suficiente humedad al área, generando una zona semiárida con bosques secos en la franja de los 1700 a los $2600 \mathrm{msnm}$., y unos páramos secos en las porciones más elevadas. En la figura 6 se muestra nuestra propuesta de sistema de vientos para el área de estudio.

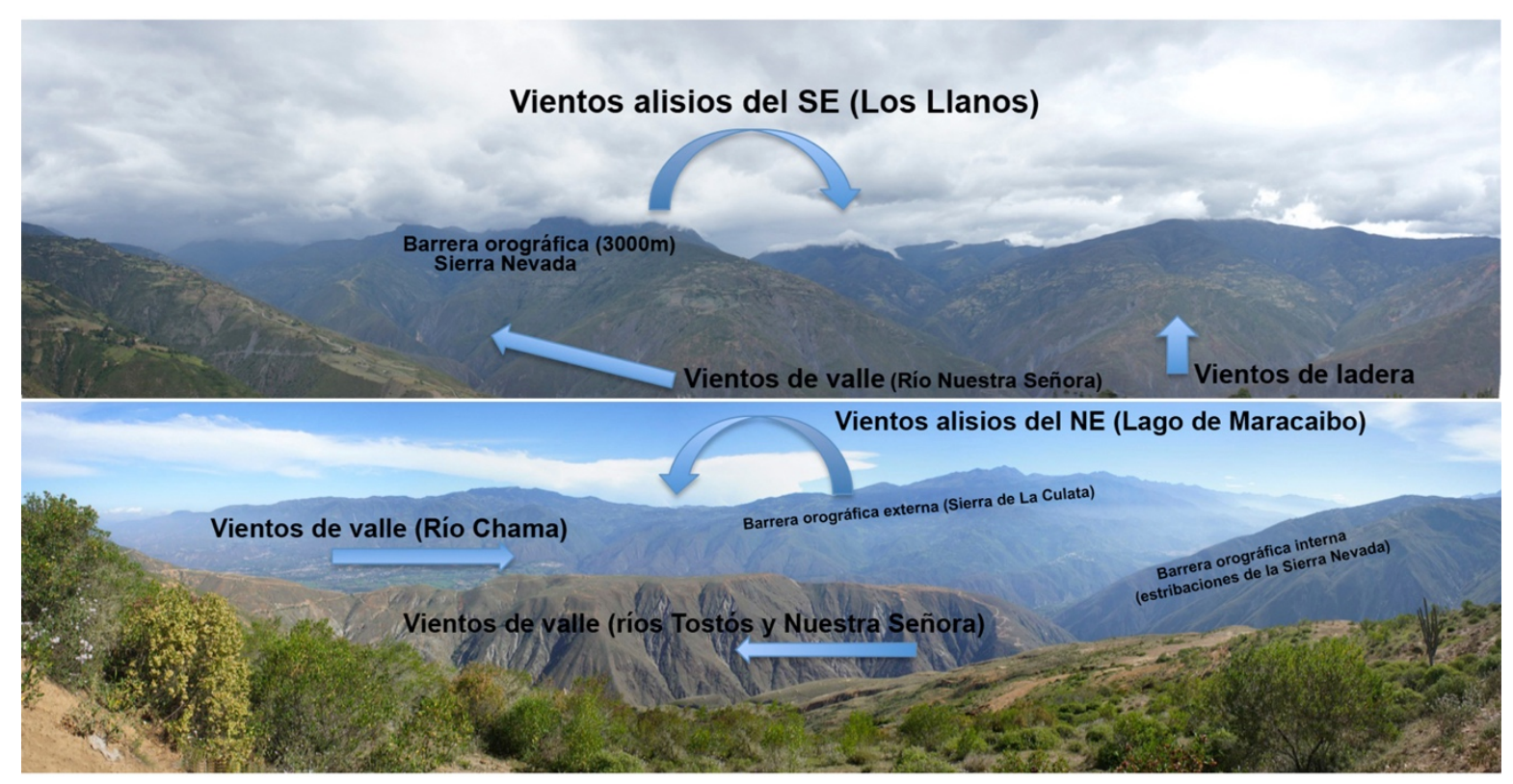

Figura 6: Propuesta de sistema de vientos que inciden sobre el área de estudio. Arriba, hipótesis de circulación de vientos dentro de la cuenca del río Chama y la subcuenca del río Nuestra señora (vista desde Mucutirís). Abajo, vientos dentro de la cuenca del río Nuestra Señora (vista desde Plan del Morro).

Fotos: E. La Marca.

\subsection{Zonas de Vida}

Para el área de estudio determinamos cuatro Zonas de Vida, de las cuales dos (la estepa espinosa Montano Bajo y la estepa Montano) no habían sido cartografiadas ni descritas en el libro clásico de Zonas de Vida de Venezuela de Ewel et al. (1976), porque a la escala de representación que emplearon (1:2.000.000) no eran cartográficamente representativas. En esta investigación estudiamos estas Zonas de Vida con un nivel de detalle mayor, se determinaron como formaciones vegetales con expresión real en el terreno y se les hizo una caracterización geográfica y ecológica. Comprobada su existencia, realizamos y aportamos por primera vez la descripción de 
estas dos nuevas zonas de vida para Venezuela. Dada la escasa cobertura geográfica y el grado de intervención que presentan las estepas Montano y espinosa Montano Bajo, y en vista de que ya existe un Libro Rojo de de los ecosistemas terrestres de Venezuela (cf. Rodríguez et al., 2010), sugerimos que estos herbazales de alta montaña sean evaluados para su posible inclusión en dicha iniciativa conservacionista. A continuación, damos detalles de las zonas de vida que se obtuvieron para el área de estudio.

monte espinoso Premontano. Se ubica en la parte más baja del área de estudio entre los 1660 y $1940 \mathrm{msnm}$, con temperatura $(\mathrm{T})$ entre 18,7 y $17,1^{\circ} \mathrm{C}$ y precipitación (PP) entre 455 y $500 \mathrm{~mm}$, provincia de humedad Semiárido. Ocupa $13,5 \mathrm{Km}^{2}$ (15\% del total del área de estudio). En esta Zona de Vida no se encuentra actualmente áreas con vegetación natural, debido a la explotación incontrolada que ha ocurrido allí durante muchos años (Ewel et al., 1976). Allí predominan las cactáceas y pequenos árboles de los géneros Capparis, Pithecolobium, Casearia y Pereskia. El pastoreo incontrolado de ganado caprino ha llevado a la pérdida de la cobertura vegetal y posteriormente a la erosión, con la formación de grandes cárcavas.

estepa espinosa Montano Bajo. Esta zona de vida era completamente desconocida para Venezuela, por lo que el nuestro constituye el primer reporte. Es la que mayor superficie ocupa, con un área de $58,1 \mathrm{~km}^{2}(64,7 \%$ del area total). Le calculamos PP entre 460 y $500 \mathrm{~mm}$ y $T$ entre 13,5 y $12^{\circ} \mathrm{C}$ y provincia de humedad Semiárido. Se localiza en gran parte del área, entre los 1960 y 2760 msnm. Aquí se encuentran los poblados de Mucumpís, Mucutirí, Acequias, San Pedro y las ruinas de San Antonio de Mucuñó, así como la Loma de Mucurute. Es oportuno recalcar que, cuando tomamos en consideración las áreas transicionales de los polígonos de Zonas de Vida, todos esos poblados caen en áreas de transición entre las Zonas de Vida estepa espinosa Montano Bajo y bosque seco Montano Bajo (Figura 7), por lo que es posible encontrar elementos florísticos característicos de ambas. Esta última zona de transición ocupa la mayor superficie dentro del área de estudio, al tener $42,3 \mathrm{Km}^{2}$ (47,2\% del área total). Predomina una vegetación de matorral xerofítico con Dodonea sp., Argemone mexicano, Cardo Santo y algunas especies espinosas. Se encuentran dispersas cactáceas del género Opuntia, así como sisales (Agave). También se presentan algunas gramíneas (Poaceae).

estepa Montano. Esta zona de vida tampoco estaba descrita para Venezuela, por lo que su caracterización en este trabajo constituye también un primer registro. Ocupa una superficie de $17,5 \mathrm{~km}^{2}$ (19,5\% del area total). Se encuentra entre los 470 y $500 \mathrm{~mm}$ de precipitación y T entre 12 y $7^{\circ} \mathrm{C}$. Se ubica en la provincia de humedad Subhúmedo. Se extiende entre 2780 y $3620 \mathrm{msnm}$, lo cual se corresponde con el límite superior del área donde se localizan los páramos de San Pedro, San Gerónimo y Piedras Blancas. En esta Zona de Vida también se localizan las cabeceras de las quebradas Mochere, Mucusás y La Capellanía, así como las partes más elevadas del Filo de Mucutirí. 
bosque húmedo Montano. Ocupa la menor superficie $\left(0,73 \mathrm{~km}^{2}\right.$ ó $0,81 \%$ del área total), a elevaciones entre 2860 y $3100 \mathrm{msnm}$, y con T entre 11,5 y $10,1^{\circ} \mathrm{C}$ y PP entre 500 y $510 \mathrm{~mm}$. Se localiza al suroeste del área de estudio en las cabeceras de la quebrada Mucumpís y al oeste del Páramo Piedras Blancas y, hacia el sur, en el Páramo de San Gerónimo. Se puede considerar como un área transicional entre bosque húmedo Montano y la estepa Montano (Figura 7).

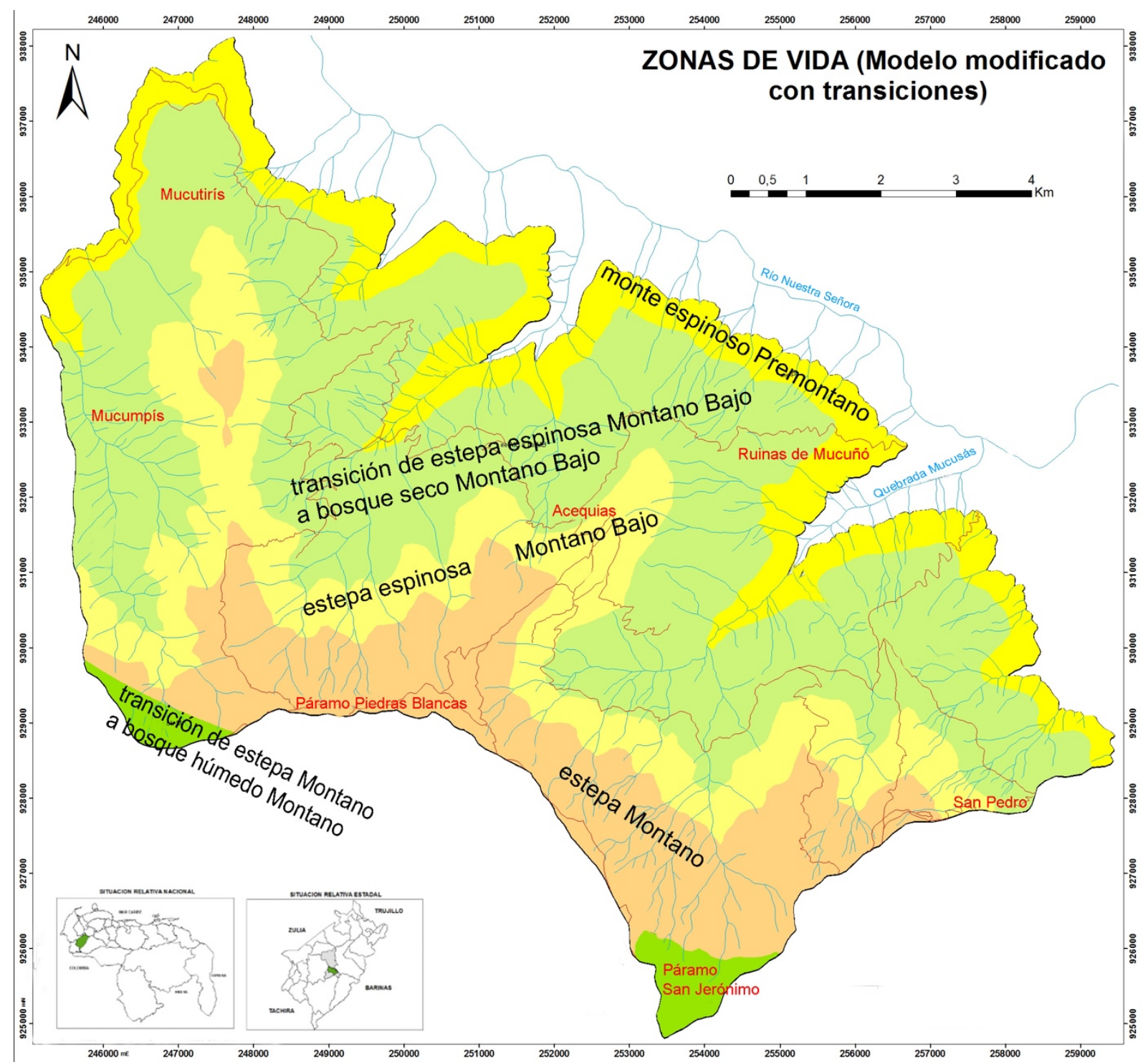

Figura 7: Zonas de Vida en el sector semiárido Acequias - San Pedro - Tostós, Pueblos del Sur de Mérida, Venezuela.

\subsection{Zonas de vida para el Último Máximo de Glaciación (UMG)}

Durante el UMG las condiciones eran más frías y secas que las actuales y, por tanto, fueron más propicias para el establecimiento de estepas. Nuestros resultados revelaron un total de cuatro zonas de vida en el área de estudio para ese período: estepa espinosa Montano Bajo, estepa Montano, monte húmedo SubAlpino y tundra muy húmeda Alpino. A continuación, detallamos cada una de ellas. 
estepa espinosa Montano Bajo. Se localizaba hacía la parte menos elevada del área de estudio entre 1660 y 1940 msnm., con T entre 13,7 y 12,1 $1^{\circ} \mathrm{C}$ y PP entre 340 y $370 \mathrm{~mm}$. Se correspondería con la provincia de humedad Semiárido. La extensión de esta zona de vida en el pasado sería de $13,4 \mathrm{Km}^{2}(14,9 \%$ del área total) y solaparía con una porción actual del monte espinoso Premontano.

estepa Montano. Era la zona de vida con mayor superficie $\left(66,3 \mathrm{Km}^{2}\right.$, casi el $74 \%$ del área de estudio), distribuida entre 1960 y $2940 \mathrm{msnm}$, con T entre 11,9 y $6,1^{\circ} \mathrm{C}$ y PP entre 345 y $380 \mathrm{~mm}$. Ubicada en la provincia de humedad Subhúmedo. Dentro de sus límites caerían los actuales poblados de Mucutirí, Mucumpís, Acequias, San Pedro, las ruinas de Mucuñó y parte del páramo de San Pedro. La distribución pasada de esta zona de vida ocupó parte de la cobertura actual de la estepa espinosa Montano Bajo y parte de la estepa Montano.

monte húmedo SubAlpino. Estaba al sur del área de estudio, entre 2960 y 3440 $\mathrm{msnm}$, con T de 5,9 a $3,1^{\circ} \mathrm{C}$ y PP entre 365 y $380 \mathrm{~mm}$. Se ubicaría en la provincia de humedad Húmedo. Esta zona de vida ocupó casi $9 \mathrm{Km}^{2}$ (o $10 \%$ del total del área) en sitios que actualmente son estepa Montano y bosque húmedo Montano. En la actualidad no existe esta Zona de Vida en toda Venezuela.

tundra muy húmeda Alpino. Ocupaba la menor extensión en el área de estudio $(1,1$ $\mathrm{Km}^{2}$, menos del $2 \%$ de la superficie total), con T media entre 2,9 y $2^{\circ} \mathrm{C}$ y PP entre 370 y 375 mm. Ocupaba los límites más altos del área, entre 3460 y 3620 msnm., donde hoy están el páramo de San Gerónimo y la naciente de la quebrada Mucucás. Esta Zona de Vida en el pasado ocupó una parte de la distribución actual de la estepa Montano, aunque en el presente esté extincta en todo el país.

El análisis de estos datos para el Último Máximo de Glaciación revela que en el área de estudio hubo otras Zonas de Vida que no existen en la actualidad, como es el caso del monte húmedo SubAlpino y la tundra muy húmeda Alpino. Así mismo, destaca que la zona de vida estepa Montano ocupó en el pasado una superficie 54,4\% mayor que la actual. No sabemos la totalidad del cambio para la estepa espinosa Montano Bajo, ya que en el pasado se desplazó probablemente mucho más abajo del área de estudio. Los cálculos indican que el límite superior de la estepa Montano estuvo ubicado $680 \mathrm{~m}$ por debajo de su límite actual, mientras que su límite inferior estuvo 820 m más abajo.

\subsection{Vegetación en las zonas de vida}

En el área de estudio se encuentra un mosaico de vegetación natural compuesto de bosques, matorrales y herbazales. El análisis de la imagen satelital indica que en el área predomina el bosque ralo (con $25,5 \mathrm{Km}^{2}$ del área total), seguidos por el matorral ralo $\left(14,9 \mathrm{Km}^{2}\right)$, herbazal $\left(13,17 \mathrm{~km}^{2}\right)$, bosque denso $\left(11,5 \mathrm{Km}^{2}\right)$, bosque medio $(8,82$ $\left.\mathrm{Km}^{2}\right)$, y matorral denso $\left(7,6 \mathrm{Km}^{2}\right)$. Hay pocas áreas bajo uso agrícola que apenas ocupan $8 \mathrm{Km}^{2}$. Los bosques pueden alcanzar desde los 1700 hasta los $3100 \mathrm{msnm}$. La vegetación de herbazal se encuentra entre 2000 y 3620 msnm. y se corresponde 
con las nacientes de las quebradas Mucumpís, Mocheré, Mucusás y La Capellanía. Estos últimos se corresponderían con lo que Monasterio (1980) identificó como "pajonales secos" o "pajonal más estépico", dominados por gramíneas en macolla, con hojas esclerófilas y estrechas (Sarmiento, 1986). El matorral denso y el matorral ralo se ubican principalmente al este del área de estudio, donde predomina la vegetación arbustiva y las gramíneas constituyen un componente importante. El primero se encuentra entre 1800 y $3100 \mathrm{~m}$ y el segundo entre 1700 y $2300 \mathrm{msnm}$. La zona agrícola se encuentra principalmente en los alrededores de San Pedro (1700 a $2900 \mathrm{~m})$.

A continuación, señalamos la correspondencia entre la vegetación encontrada en el campo y las Zonas de Vida resultantes de la aplicación del modelo bioclimático. El monte espinoso Premontano, al noroeste del área, se presenta en unos sitios como un mosaico entre vegetación propia de monte espinoso Premontano y aquella del bosque seco Premontano, mientras que en otros predominan comunidades propias de bosque seco Montano Bajo. En aquellos sitios generalmente cercanos a cursos de agua, con una combinación de pendientes muy pronunciadas y posiciones de umbría (que son una minoría de casos), este bosque se encuentra en estado natural, mientras que en otros sitios la vegetación ha sido muy intervenida (Figura 8). Esta vegetación azonal boscosa obedece a una combinación de pendientes muy pronunciadas, posiciones de umbría y cercanía a escorrentías. Por el contrario, al noreste del área, el déficit de humedad es más acentuado, y allí sí se observa un predominio de comunidades típicas del monte espinoso Premontano, aunque presenta un alto grado de intervención y fuerte carcavamiento.

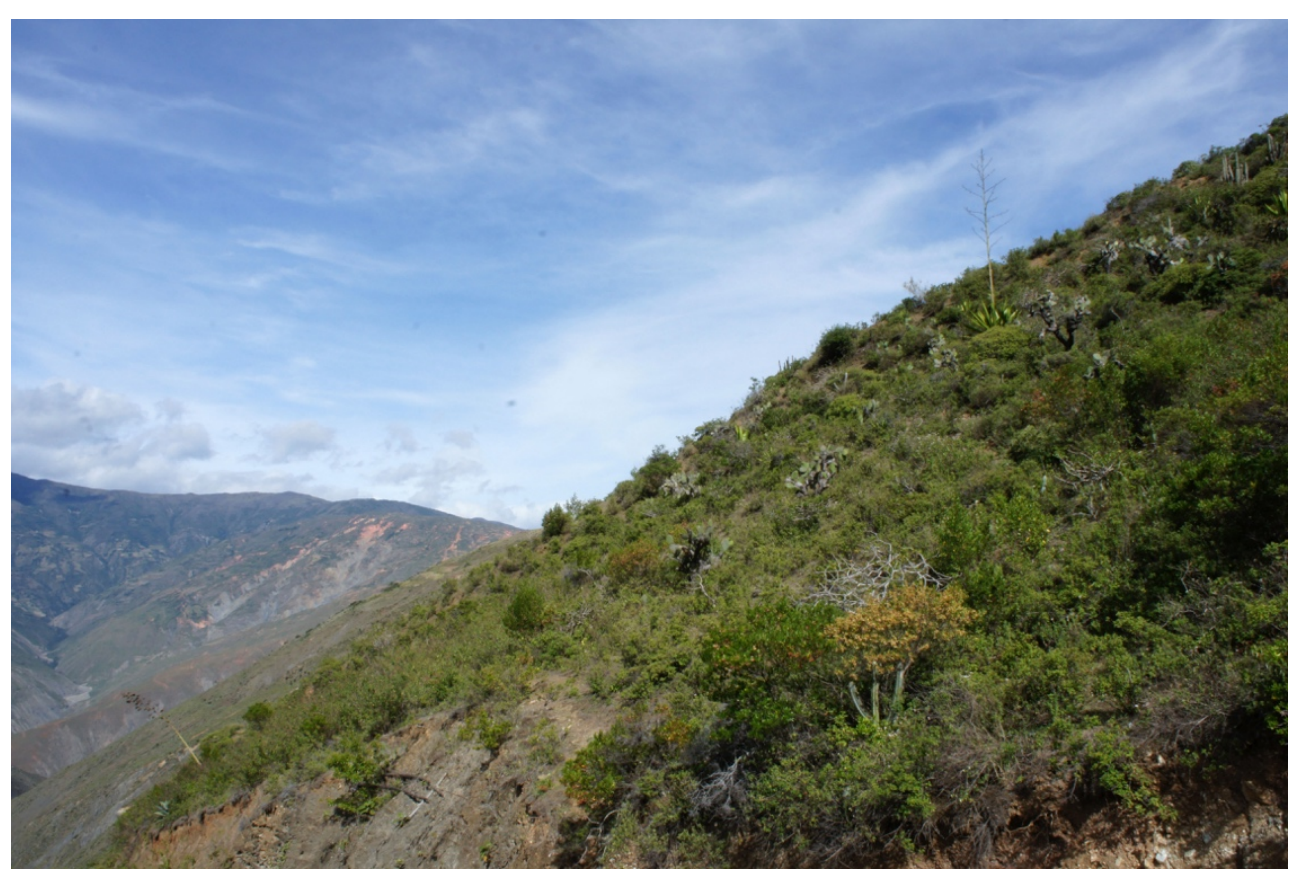

Figura 8: Zona de vida monte espinoso Premontano, en las cercanías de El Morro, $1880 \mathrm{msnm}$.

Foto: E. La Marca 
Dentro de la Zona de Vida estepa espinosa Montano Bajo en transición con bosque seco Montano Bajo, en las ruinas de San Antonio de Mucuñó, se observó un tipo de vegetación arbustiva con algunas especies espinosas y un solo árbol de "dividive" (Caesalpinia sp.). Dicha vegetación se asemeja más a la típica zona de vida estepa espinosa Montano Bajo. En este sector los vientos son muy fuertes (sometidos al efecto Foehn) y pueden llegar a desecar la vegetación. Debido a los cielos despejados, durante todo el día esta área está expuesta a la insolación, lo cual puede contribuir a una mayor evapotranspiración que favorece el establecimiento de especies xerófilas. En algunos lugares el grado de intervención es muy marcado (posiblemente por un aprovechamiento agrícola que data de tiempos pre-hispánicos).

La disparidad en la vegetación entre el sector noreste y el noroeste de la transición de estepa espinosa Montano bajo a bosque seco Montano Bajo puede obedecer a razones climáticas. Así, el noreste del área puede tener una mayor influencia de precipitaciones más bajas, que ayudaría en parte a que se establezca una vegetación más seca. Por el contrario, el noroeste del área tendría la influencia de precipitaciones un poco mayores que contribuirían, en conjunción con otros factores ya nombrados, al establecimiento del bosque seco. Estos bosques secos azonales constituyen una asociación atmosférica.

En la zona de vida estepa espinosa Montano Bajo, se observa un mosaico entre elementos típicos de comunidades de estepa espinosa Montano Bajo y de bosque seco Montano Bajo (Figura 9). Contradictoriamente, las especies de bosque seco son las que predominan en esta zona de vida, fenómeno que es más acentuado hacia el oeste del área de estudio. Esta diferencia de vegetación dentro de una misma zona de vida pudiera ser explicado por la influencia de asociaciones atmosférica e hídrica, que hace que haya más disponibilidad de humedad en el ambiente que lo registrado por las estaciones distantes. Por otro lado, las comunidades identificadas como estepa espinosa ocupan una menor superficie y sólo se encuentran hacia el este, donde esta vegetación se hace más arbustiva y más densa a medida que se acerca al límite superior de la Zona de Vida. A pesar de ser esta última la vegetación zonal esperada, no estamos seguros cuál pudo haber sido la vegetación natural en la misma ya que gran parte de la vegetación ha sido intervenida. De hecho, por ahí transcurre la via entre Acequias y San Pedro, dos de las poblaciones más antiguas de los Andes venezolanos.

El bosque seco encontrado en la zona de vida estepa espinosa Montano Bajo puede deberse a una asociación hídrica, atmosférica, o ambas. La asociación hídrica estaría condicionada por los cursos de agua que favorecerían un mejor desarrollo de bosques, que dispondrían de mayor humedad durante toda o la mayor parte del año. La asociación atmosférica se generaría por los vientos locales que se forman en la cuenca del río Nuestra Señora. Estos, a medida que ascienden se cargan de la humedad proveniente de la evapotranspiración y a partir de 1800 hasta los 2600 msnm aportan dicha humedad al ambiente por condensación. A pesar que esta explicación sería igualmente válida para suponer la existencia de un bosque seco en estas elevaciones al este del area de estudio, cabe destacar que allí se da una estepa 
espinosa porque los vientos en esta área soplan tan fuerte que le roban mayor humedad a las plantas, aunado a la alta insolación que incide en que la evapotranspiración sea mayor.

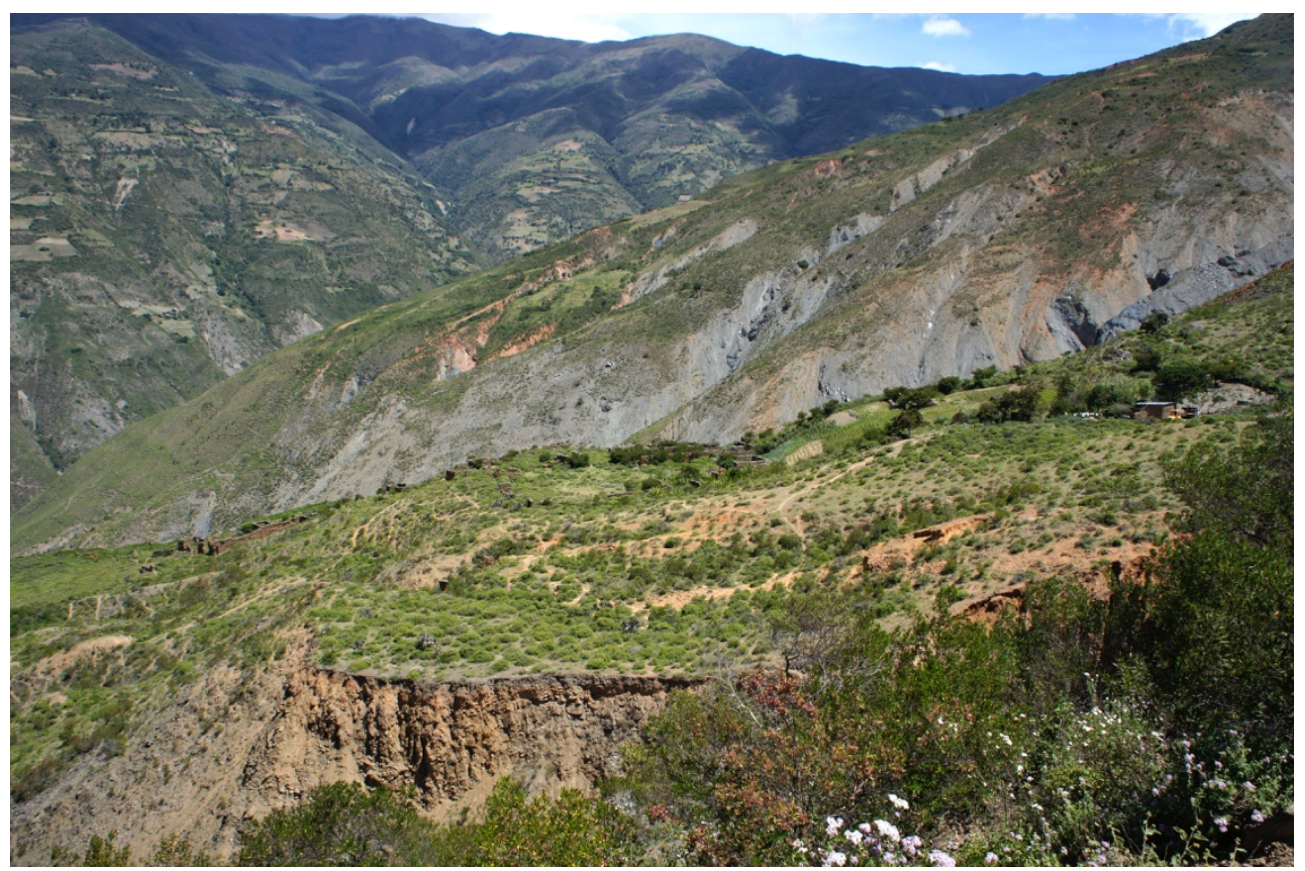

Figura 9: Vista general de la estepa espinosa Montano Bajo (en transición con bosque seco Montano Bajo) en las ruinas de Mucuñó.

Foto: E. La Marca.

En la zona de vida estepa Montano conseguimos igualmente una discrepancia en la vegetación esperada. En el páramo Piedras Blancas la vegetación se corresponde con la asociación climática climax, con predominio de gramíneas en macolla y baja presencia de frailejones (Figura 10). La impresión general del paisaje es la de un páramo seco, pobre en especies. En los límites más bajos de esta Zona de Vida (por encima de $2780 \mathrm{msnm}$ ) se observa un bosque seco. En teoría, en este piso altitudinal no se puede dar bosques secos; por el contario, si hay suficiente aporte de humedad se establecería un bosque húmedo Montano. Sin embargo, las condiciones secas imperantes en este sector no permiten el desarrollo de un bosque húmedo. La presencia de un bosque seco en lugar de una estepa en estos lugares puede explicarse como una asociación atmosférica formada por los últimos aportes de humedad de los vientos de valle ascendentes. En el páramo de San Gerónimo se presenta un tipo de vegetación con mayor abundancia de frailejones y arbustos leñosos, aunque hay una menor cobertura de gramíneas. Esta vegetación azonal estaría influenciada por una asociación atmosférica que se origina por los vientos cargados de humedad que, subiendo desde los Llanos por la cuenca del río Mucuchachí, condensan en las altas montañas y se establecen como nubes orográficas 'residentes' que constantemente aportan humedad extra al ambiente. 


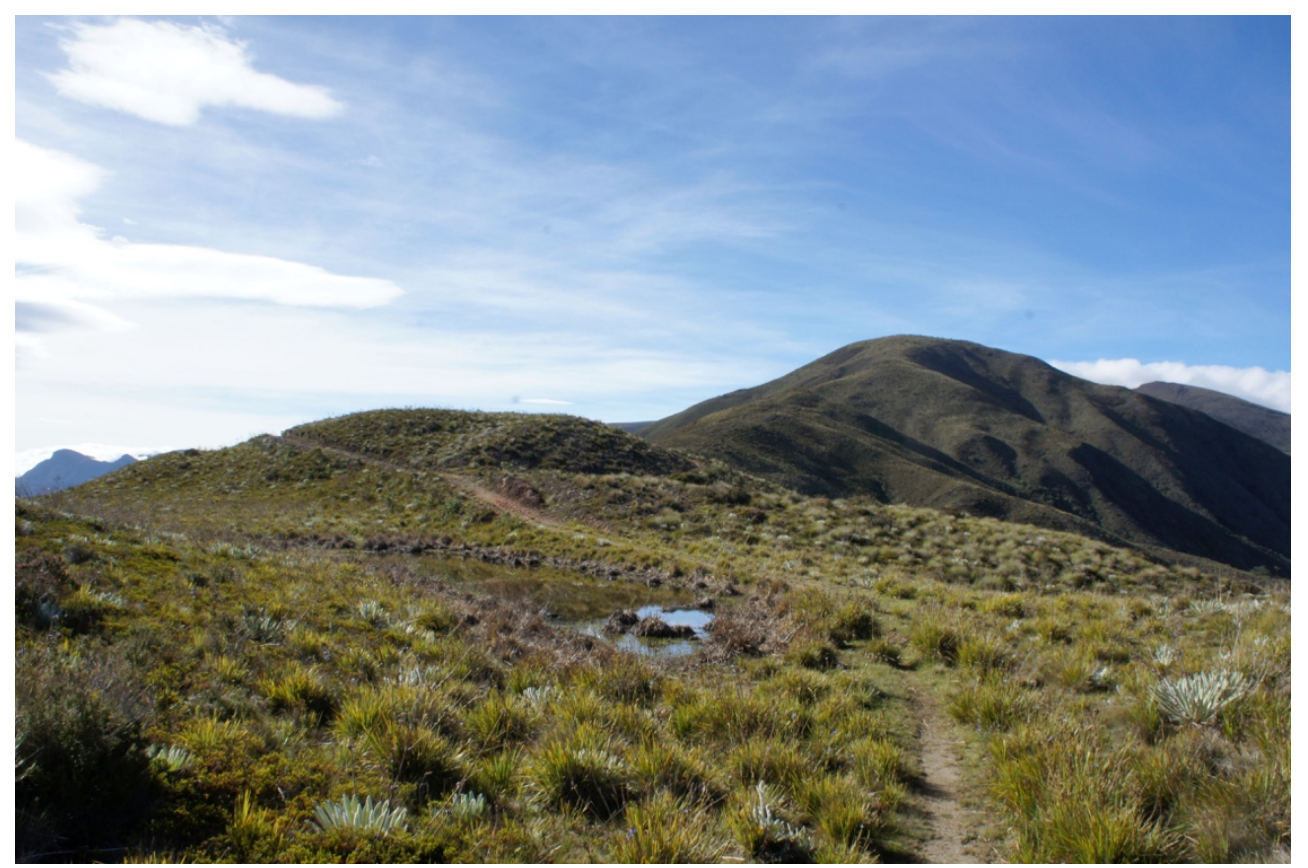

Figura 10: Vista general de la estepa Montano en el Páramo Piedras Blancas, en el camino que conduce entre Acequias y la laguna Las Lajas.

Foto: E. La Marca.

En la transición estepa Montano a bosque húmedo Montano se encuentra una vegetación de tipo páramo húmedo. Aunque, por lo inaccesible, no se pudo examinar directamente en el sitio la vegetación del sector del páramo Piedras Blancas, con binoculares detectamos una vegetación baja con frailejones y gramíneas. La imagen de satélite Spot $8 \mathrm{~m}$, año 2010, revela la presencia adicional de un bosque, probablemente un bosque seco como el que predomina en ambientes inmediatamente por debajo. En el Páramo San Gerónimo conseguimos una mayor presencia de frailejones y arbustos, así como pocas gramíneas. La mayor diversidad de especies y la cobertura más densa puede explicarse como una asociación atmosférica que involucra los vientos húmedos provenientes de los Llanos. En las cercanías del Páramo Piedra Pirela, fuera del área de estudio, aunque relativamente próximo geográficamente, encontramos una vegetación de páramo que se correspondería con la Zona de Vida estepa Montano en transición con bosque húmedo Montano (Figura 11). 


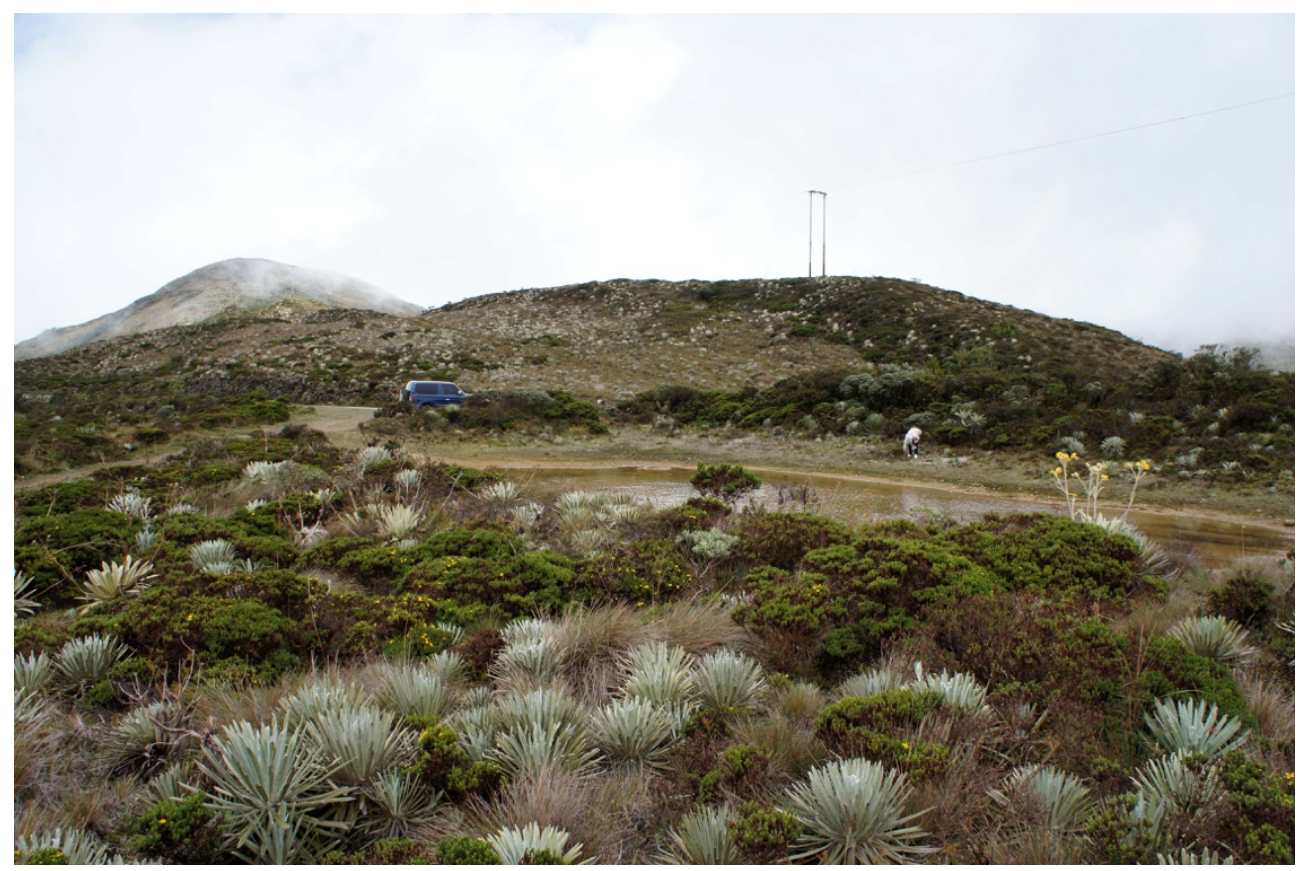

Figura 11: Zona de transición entre estepa Montano y bosque húmedo Montano, en parque Piedra Pirela (San José de Acequias). Nótese la mayor diversidad de especies en este páramo húmedo.

Foto: Enrique La Marca.

\section{Conclusiones}

Las áreas intra-andinas secas se localizan en varios países de los Andes del Norte; en Venezuela, una de las más importantes está ubicada en la cuenca del río Chama, en el estado Mérida. Esta es el producto de la interacción de factores del clima con el relieve local. Nuestro estudio geográfico-ecológico a escala 1:25.000 en un sector ubicado entre las poblaciones de Tostós, Acequias y San Pedro, en la región de los Pueblos del Sur de Mérida, reveló la existencia de varias formaciones vegetales adaptadas a esas condiciones secas. Aplicando el modelo de Zonas de Vida de Holdridge, esas formaciones se correspondieron principalmente con el monte espinoso Premontano, la estepa espinosa Montano Bajo, y la estepa Montano. Estas dos últimas destacan porque por vez primera son reportadas para Venezuela, lo cual constituye un hallazgo biogeográfico único para el país. Recomendamos la protección integral de estas dos nuevas Zonas de Vida, a través de su incorporación al Parque Nacional Sierra Nevada, cuyos límites están en las cercanías.

Con esta investigación, por consiguiente, se adicionan dos Zonas de Vida nuevas para Venezuela, que logra así un total de 24, de las cuales 20 corresponden al estado Mérida (destacando su biodiversidad). Es interesante notar que las dos nuevas Zonas de Vida son remanentes de formaciones vegetales que tuvieron una mayor extensión en el pasado. Una reconstrucción para el Último Máximo de Glaciación sugiere que la estepa espinosa Montano Bajo y la estepa Montano tuvieron una extensión mayor y estuvieron ubicadas a una elevación menor; así mismo para ese período aparecieron dos zonas de vida adicionales, el monte húmedo SubAlpino y la tundra muy húmeda Alpino, que ya no existen en la actualidad. 


\section{Bibliografia}

Andressen, R. (2009). Circulación atmosférica. En Fundación Empresas Polar (Ed.). GeoVenezuela (pp. 238-328). Vol. 6. Capítulo 13. Editorial ExLibris, Caracas.

Ewel, J., Madriz, A., Tosi, J. (1976). Zonas de Vida de Venezuela. Memoria explicativa sobre el mapa ecológico. Editorial Sucre. Segunda Edición. Caracas, Venezuela.

La Marca, E. (1997). Origen y Evolución Geológica de la Cordillera de Mérida. Cuadernos de la Escuela de Geografía, nº 1. Universidad de Los Andes. Mérida, Venezuela.

Monasterio, M. (1980). Las formaciones vegetales de los páramos de Venezuela. En M. Monasterio (Ed.). Estudios Ecológicos en Los Páramos Andinos (pp. 93-158). Ediciones de la Universidad de Los Andes, Mérida, Venezuela.

Monasterio, M., Reyes, S. (1980). Diversidad ambiental y variación de la vegetación en los páramos de los Andes venezolanos. En M. Monasterio (Ed.). Estudios Ecológicos en Los Páramos Andinos. (pp. 47-91). Ediciones de la Universidad de Los Andes, Mérida, Venezuela.

Rodríguez, J. P., Rojas-Suárez, F., Giraldo Hernández, D. (2010). Libro Rojo de los Ecosistemas Terrestres de Venezuela. Provita, Shell Venezuela, Lenovo Venezuela. Caracas, Venezuela.

Santiago-Paredes, S., La Marca, E. (2007). Comportamiento del clima a finales del siglo XX en los altos Andes venezolanos y el declive de Atelopus mucubajiensis. Herpetotropicos, $3(1), 7-20$.

Sarmiento, G. (1986). Ecological features of climate in high tropical mountains. En F. Vuilleumier y M. Monasterio (eds.). High Altitude Tropical Biogeography (pp. 11-45). Oxford University Press y The American Museum of Natural History. New York, Oxford.

Schubert, C., Vivas, L. (1993). El Cuaternario en la Cordillera de Mérida. Andes venezolanos. Universidad de Los Andes, Fundación Polar. Talleres Gráficos Universitarios, Mérida.

Van der Hammen, T. (1974). The Pleistocene changes of vegetation and climate in tropical South America. Journal of Biogeography, 1, 3-26.

Veillon, J. P. (1989). Los Bosques Naturales de Venezuela. Parte I. El Medio Ambiente. Instituto de Silvicultura, Universidad de Los Andes, Mérida, Venezuela.

Vivas, L. (1992). Los Andes Venezolanos. Academia Nacional de la Historia. Caracas.

\section{Agradecimientos}

La Escuela de Geografía de la Universidad de Los Andes en Mérida, Venezuela, brindó apoyo logístico para el desarrollo de esta investigación. Los profesores y amigos Ernesto Flores y Juan Carlos Gavidia nos dieron su apoyo en las salidas de campo y apoyaron con la cartografía y la identificación de especies vegetales. Gustavo Silva suministró valiosos datos climáticos; y los geógrafos Daniela Palazzo y Greis Graterol gentilmente nos apoyaron en diversas tareas en pro de nuestros objetivos. Por último, agradecemos a los amables pobladores de Tostós, Acequias y San José de Acequias (en especial al Sr. Martín Sosa de la posada Mochabá) por todas las 
cortesías brindadas. Dos revisores anónimos hicieron valiosas críticas que mejoraron el manuscrito original. A todos ellos, y a muchas otras personas que colaboraron en diferentes aspectos, les estamos muy agradecidos.

Artigo recebido em / Received on: 13/08/2019

Artigo aceite para publicação em / Accepted for publication on: 22/10/2019 
La Marca e Contreras / Physis Terrae, Vol. 1, $n^{\circ}$ 1, 2019, 121-139

Página intencionalmente deixada em branco 